This is a post-peer-review, pre-copyedit version of a paper published in Kurbanoğlu S, Špiranec S, Ünal Y, Boustany J, Huotari M, Grassian E, Mizrachi D \& Roy L (eds.) Information Literacy in Everyday Life. Communications in Computer and Information Science, 989. ECIL 2018: 6th European Conference on Information Literacy, Oulu, Finland, 24.09.2018-27.09.2018. Cham, Switzerland: Springer Verlag, pp. 73-82. The final authenticated version is available online at: https://doi.org/10.1007/978-3-030-13472-3_7

\title{
Character Building in Children's Online Information Behaviours: Applying a Virtue Epistemology Perspective to Information Literacy
}

\author{
David McMenemy', Steven Buchanan' \\ 'Strathclyde iSchool Research Group, University of Strathclyde, Glasgow, UK \\ \{d.mcmenemy, steven.buchanan\} estrath.ac.uk

\begin{abstract}
This paper advances our understanding of the theoretical and practical challenges of developing intellectual character in children's online information behaviours. We argue that widely reported issues such as misinformation and disinformation extend IL education beyond considerations of ability to considerations of disposition, and highlight this as an understudied topic within IL education. We introduce the classical concept of intellectual character and discuss virtues traits in the IL context. Applying Baehr's nine intellectual virtues to two commonly cited IL models, we evidence limited presence of virtues in IL models, and propose an important agenda for future research.
\end{abstract}

Keywords: Digital citizenship; virtue ethics; information literacy; information behaviour, virtue epistemology; children.

\section{Introduction}

This paper advances our understanding of the theoretical and practical challenges of developing intellectual character in children's online information behaviours. Character is understood as "the comprehensive set of ethical and intellectual dispositions of a person" [1]. In relation, intellectual character "is the part of your character-your dispositions to act, think, and feel - that pertains to thinking and learning" [2, p.18]. The authors position intellectual character as a topic of significant societal concern. Issues in the online information behaviours of children are reported globally, ranging from access (e.g., obtaining) to use (e.g., application) to conduct (e.g., respect). For example, a recent UK national report identifies common issues of misinformation, hate speech, sexting, and cyberbullying amongst children [3]; and another that as many as one in four young people in the UK have experienced cyberbullying [4]. Similar cyberbullying rates are reported in many other countries, e.g., Australia and the USA, and South Africa, rising to $43 \%$ in Serbia, and $77 \%$ in Argentina [5-7]. Issues of disinformation for malicious purposes are also reported [8]. 


\section{Background}

Whilst intellectual character is positioned by the authors as an important aspect of information literacy (IL) education, it would also appear to be an understudied topic within the discipline. Reviews of the main library and information science databases, Library and Information Science Abstracts (LISA) and Library, Information Science, and Technology Abstracts (LISTA) were conducted Spring 2018, encompassing the entire collections to date. Searches combined IL with relevant epistemological keywords (discussed in 3.1) including: virtue epistemology; virtue ethics; character.

Notably, limited specific reference and/or discussion of intellectual character was found. For example, virtue epistemology produced two precise hits on LISA (one a general review of Baehr's book, and the other a brief reference to Zagzebski) and three precise hits on LISTA, two of which were further reviews of Baehr's book, and the other related to cultivating online enlightenment from a Buddhist perspective. Ethical values related to social justice have received some attention [9-15], but relate to ethical aspects of character, not intellectual.

Similar concerns regarding a lack of attention to issues of intellectual character have been raised within education more broadly. For example, Dow argues that "there is a striking lack of familiarity with matters of intellectual character and virtue at the academic and popular levels" within education [16, p.16]. Other researchers have observed the "constantly evolving legitimating principles of character education and their continued non-appearance on education-policy and teacher-training agendas" [17, p.79]. Consequently, this paper asks two fundamental research questions: (1) What are the desirable intellectual character traits applicable to children's online information behaviours? (2) How is the development of desirable intellectual character traits currently addressed within IL education?

\section{$3 \quad$ Methodology}

In this initial exploratory study, we sought to identify and understand concepts of character in the IL context, and explore presence of character concepts in IL models.

\subsection{Theoretical framework}

Our interdisciplinary framework brings together theories and models of information literacy with theories and models of virtue epistemology to explore shared concepts of knowledge acquisition and sharing. Virtue epistemology (VE) relates virtue (i.e. the traits of a moral person) to knowledge, and knowledge acquisition pursuits. VE in the knowledge acquisition context, "requires that we think, reason, judge, evaluate, read, interpret, adjudicate, search, or reflect in various ways," with particular attention to aspects of personal and intellectual character [18, p.18]. VE is placed in the educational context via the use of Baehr's [2] framework of nine core virtues: curiosity; intellectual autonomy; intellectual humility; attentiveness; intellectual carefulness; intellectual 
thoroughness; open-mindedness; intellectual courage; and intellectual tenacity.

Our IL definition is provided via the UK Chartered Institute of Library and Information Professional's (CILIP) Information Literacy Group (ILG) definition, which states that: "Information literacy is the ability to think critically and make balanced judgments about any information we find and use" [19]. The CILIP ILG definition, with emphasis on critical thinking and balanced judgment, appeared particularly appropriate due to potential synergy with open-mindedness aspects of VE. Other IL definitions, while similar, possess less synergistic use of language. For example, the American Library Association define IL as [20], "a set of abilities requiring individuals to recognize when information is needed and have the ability to locate, evaluate, and use the needed information effectively."

\subsection{Identifying character concepts in information literacy models}

Baehr's nine core virtues provided a conceptual framework for identifying concepts of character development in information literacy (IL) models. The IL models selected for analysis were the Big6, and the ACRL Framework; representing two commonly cited models widely used in education. Content analysis was identified as an appropriate method for identifying the presence of character concepts in IL models.

Content analysis "is a research technique for the objective, systematic and quantitative description of the manifest content of communication" [21, p.18]. It provides a method to "quantify content in terms of predetermined categories and in a systematic and replicable manner" [22, p.689]. However, it is important to note that whilst quantifying content, our approach to coding also incorporated qualitative analysis and extended beyond identification of manifest content to latent content facilitating an interpretative approach to content analysis [22]. Manifest content refers to exact or close matches, the latter extending to synonymous terms. Latent content refers to matches expressed in different terms but with shared meaning. Whilst open to interpretation, analysis of latent content was considered important given the cross-disciplinary nature of this study and the potential for variance in articulation of character concepts. Periodic code checking (multiple sample coding), was conducted by one team member independent to the first to validate coding, with no notable variations found. Our initial focus was the identification of presence of concepts. We reserve further examination (e.g. exploration of prescriptive depth of character concepts) for future work.

\section{Character}

Character has long been discussed, and long recognised as something to be nurtured in children. For example, in the Nichomachean Ethics, Aristotle explored the importance of human virtue for the cultivation of the virtuous citizen. For Aristotle, virtue fell "into two divisions, intellectual excellence and goodness of character" [23]. Aristotle believed that virtuous behaviours were gained by repetition and training: "the virtues are not formed in us by nature, but they result from our natural capacity to acquire them when that capacity has been developed by training" [23]. Importantly, bad habits could 
be formed in a similar way, "as [bad] habits of character are formed as the result of conduct of the same kind" [23]. Consequently, Aristotle believed that the cultivation of virtue in the young was something of "supremest importance" [23].

Cultivation of virtue to foster citizenship must now consider behaviours in both the physical and digital space, and the concept of digital citizenship, now considered crucial for future generations [24]. Further, issues such as cyberbullying and misuse of information extend IL education beyond considerations of ability (i.e. skills) to considerations of intellectual character (i.e. desirable or virtuous dispositions).

\subsection{Baehr's 9 core virtues}

Baehr's research on VE led to a widely cited book in 2011, followed by a project, "Intellectual Virtues in Education," which investigated the application of virtue epistemology theories within educational practices. This led to the formation of a US middle school which teaches based on VE theories. In addition, Baehr has produced a practical guide for applying VE in the educational setting. Baehr is thus selected as a theoretical model that has successfully put character concepts into educational practice.

Baehr provides two classifications of intellectual virtues. The first is a set of 9 core virtues arranged under three groupings related to the knowledge-building process. The second provides a further more detailed exposition of intellectual virtues divided into 6 categories [2]. For the purposes of this study the first classification is considered sufficient to introduce core intellectual character concepts and guide analysis of IL models. Each of the nine core virtues are discussed below and are placed in the information behaviour context by identifying related concepts within two commonly cited models of information behaviour: Wilson's [25] model of information behaviour; and Kuhlthau's model of the information search process [26].

Baehr's first grouping identifies intellectual character virtues required for initiation of knowledge acquisition and ongoing direction:

a. Curiosity - relates to being "driven to explore and expand their mind" [2, p.59]. For Baehr this "occupies a special role in the overall economy of learning" [2, p.59]. Unlike those who are curious only for extrinsic reasons such as prescribed tasks, Baehr argues that, "fostering curiosity is akin to fostering a 'love of the game' in sports” [2, p.59-60]. For Baehr, curiosity is motivated by a desire for genuine, and broad, understanding.

b. Intellectual autonomy - describes "a willingness and ability to think for oneself" [2, p.70]. Baehr argues that, "like all the other virtues, [autonomy] needs to be balanced and constrained by complementary virtues, in this case virtues like intellectual humility... We need to be aware and accepting of our intellectual limitations and deficiencies" [2, p.72].

c. Intellectual humility - refers to"an alertness to and willingness to "own" one's intellectual limitations, weaknesses, and mistakes" [2, p.81]. Baehr argues that the "intellectually humble person, instead of trying to steer the conversation away from his ignorance, will seek to replace it with knowledge or understanding" [2, p.81].

In information behaviour terms, curiosity is recognised as a psychological motivation 
that can activate and drive information-seeking activity [25-26]. Intellectual autonomy can be related to aspects of self-efficacy [25], and intellectual humility to knowing one's limitations, and being willing to seek out assistance when experiencing uncertainty [26].

Next, Baehr identifies virtues required for continued progress, and in particular, depth of understanding:

d. Attentiveness - relates to the individual being "present in the sense that he's personally engaged and invested in what's being said or learned" [2, p.94]. According to Baehr, the attentive student "listens carefully and openly" [2, p.94].

e. Intellectual carefulness -is present when the "person takes pains to avoid making intellectual mistakes... [and] also has a grasp of the rules of good thinking and related intellectual activities" [2, p.105].

f. Intellectual thoroughness - is present when the "person is disposed to probe for deeper meaning and understanding" [2, p.117].

In information behaviour terms, attentiveness can be related to active and constructive information seeking behaviours [25-26]. Intellectual carefulness and thoroughness can be considered in relation to the process of constructing meaning from new information, and inherent reflective practices and expansive information searches [26].

Finally, Baehr identifies virtues for overcoming obstacles throughout the learning process:

g. Open-mindedness - refers to a "person is one who is willing and able to consider alternative standpoints, to give them a fair and honest hearing, and to revise her own standpoint or beliefs accordingly" [2, p.126].

h. Intellectual courage - refers to, "when we subject ourselves to a potential loss or harm in the context of a distinctively intellectual pursuit like learning or inquiring after the truth" [2, p.139].

i. Intellectual tenacity - is present when a "person doesn't give up when she doesn't understand something. Nor does she treat intellectual failure or defeat as a final judgment of her abilities." [2, p.150].

In information behaviour terms, open-mindedness can be related to exploratory and expansive information seeking actions [26]. Intellectual courage and tenacity can be considered in relation to stress/coping mechanisms influencing subsequent information behaviours [25], and resilience to uncertainty including new knowledge that can challenge existing personal constructs [26].

\section{$5 \quad$ Character in information literacy models}

We now discuss our findings related to the presence of Baehr's nine core virtues in the Big6 model and the ACRL framework.

\subsection{The Big6}

The Big6 is a widely-used "six-stage model to help anyone solve problems or make decisions by using information" [27] developed by by Eisenberg and Berkowitz [28- 
29]. The model is built around what are described as the six big skills of informationproblem-solving: task definition, information seeking strategies, location of and access to information, use of information, synthesis, and evaluation. The focus of the model is "on developing broad skills areas reflecting the information problem-solving process rather than teaching how to use specific resources, tools, or library systems" [28, p.100].

None of the 9 core virtues were manifest within the Big6. Latent analysis also failed to identify virtues with any degree of confidence. For example, for the first step in the Big6 model, task-definition, it is stated that, "Before using any other information skill, students must first be able to articulate information needs" [28, p.115]. Within the objectives listed for this skill, the focus is on a specific information-seeking problem, and thus has limited interpretation. This was the case across all Big6 steps. Perhaps the closest to a degree of interpretation as incorporating character concepts was step two, information-seeking strategies, which suggests, "examining alternative approaches to the problems of acquiring appropriate information" [28, p.110], which could arguably be associated with virtues of open-mindedness, intellectual autonomy, and intellectual humility. However, again the description of the skill is focused on meeting an individual task as opposed to developing knowledge acquisition. Overall the Big6 was found to be task-focused, and thus limited in relation to character development.

\subsection{ACRL Framework for Information Literacy for Higher Education}

The ACRL Framework [30] is a development of the Information Literacy Competency Standards for Higher Education first published in 2000. The current Framework was adopted by ACRL in 2016, and has six frames that form the basis: Authority Is Constructed and Contextual; Information Creation as a Process; Information Has Value; Research as Inquiry; Scholarship as Conversation; Searching as Strategic Exploration. An important point to note about the fit of the Framework for a virtue epistemology approach is that it refers to the expected skills that should be acquired as "dispositions." This is a potential indication that the approach taken in the development of the Framework is cognisant of character issues. None of the 9 core virtues were manifest within the ACRL Framework; however latent analysis identified several relationships.

The first frame, "Authority Is Constructed and Contextual", relates to the credibility and construction of information, and recognising what levels of authority are required for different kinds of information need. There is latent presence of several virtues. Specifically, the following except supports both open-mindedness, and intellectual carefulness: "Experts view authority with an attitude of informed skepticism and an openness to new perspectives, additional voices, and changes in schools of thought." This mirrors Baehr's notion that, "the "intellectually careful person takes pains to avoid making intellectual mistakes... [and] also has a grasp of the rules of good thinking and related intellectual activities" [2, p.105]. It also reflects Baehr's summation of open-minded people as "willing and able to consider alternative standpoints, to give them a fair and honest hearing, and to revise [their] own standpoint or beliefs accordingly" [2, p.126].

The second frame, "Information Creation as a Process", focuses on the process of creating information in multiple formats, and the awareness in the researcher of that 
process: "experts look beyond format when selecting resources to use." While we recognise it could be argued that this could be described as an aspect of intellectual thoroughness or intellectual carefulness, the frame relates to skills as opposed to dispositions, and thus is not considered to incorporate aspects of intellectual character.

The third frame, "Information Has Value", relates to the value of information on multiple fronts, from economic to social, to legal: "the individual is responsible for making deliberate and informed choices about when to comply with and when to contest current legal and socioeconomic practices concerning the value of information." This was not found to have presence of any of the core virtues.

The fourth frame, "Research as Inquiry", relates to the process of research as being iterative and about complex or emerging questions. Several core virtues are present latently within this frame. The virtue of curiosity is present in the statement that, "Experts see inquiry as a process that focuses on problems or questions in a discipline or between disciplines that are open or unresolved." This mirrors Baehr's notion that "a curious person is disposed to wonder, ponder, and ask why... to know how or why things are the way they are" [2, p.61]. We can also see both intellectual humility, and openmindedness in the following summary of the process of inquiry: "this process includes points of disagreement where debate and dialogue work to deepen the conversations around knowledge."

The fifth frame, "Scholarship as Conversation", relates to the cultivation of scholarship as discourse between different minds. This frame is supported by several of the core virtues. It presents scholarship as "a discursive practice in which ideas are formulated, debated, and weighed against one another over extended periods of time" and this can be clearly linked to open-mindedness, intellectual humility, intellectual carefulness, and intellectual thoroughness. In addition, that, "Experts understand that, while some topics have established ... query may not have a single uncontested answer. Experts are therefore inclined to seek out many perspectives, not merely the ones with which they are familiar." This mirrors Baehr's insistence that the intellectually thorough person probes for "deeper meaning and understanding" [2, p.117]. On intellectual humility, and again, open mindedness, we can identify the virtues in sentences like: "develop awareness of the importance of assessing content with a skeptical stance and with a self-awareness of their own biases and worldview."

Lastly, "Searching as Strategic Exploration" emphasises the potential complexity of seeking out information and the skills necessary in understanding that overall process. It states that, "Searching for information is often nonlinear and iterative, requiring the evaluation of a range of information sources and the mental flexibility to pursue alternate avenues as new understanding develops." There is latent presence here of intellectual humility, as Baehr suggests the intellectually humble person, "instead of trying to steer the conversation away from his ignorance, will seek to replace it with knowledge or understanding, possibly by noting his ignorance and asking others to fill in the gap" [2, p.80].

\section{Discussion}


The development of intellectual character in children can be considered in relation to nine virtues [2]: curiosity; intellectual autonomy; intellectual humility; attentiveness; intellectual carefulness; intellectual thoroughness; open-mindedness; intellectual courage; and intellectual tenacity. We have positioned these virtues as core to the development of desirable online information behaviours in children, but in relation, we report a lack of previous studies within IL education, and identify limited presence of such virtues within our sample of IL models.

Within the Big6 only one step, 'information-seeking strategies', could be loosely associated with virtues of intellectual autonomy and humility, and openmindedness; however, relations are not explicit and subject to interpretation. Within the ACRL we identified virtues latently present within the descriptions of the frames. The most common virtues related to open-mindedness and intellectual humility. Relationships to intellectual carefulness, curiosity, and thoroughness were also identified. However, several of these relations are not explicit and subject to interpretation. This could be interpreted as a usage of the terminology of virtue without a clear connection to the epistemological meaning. Baehr argues that using the language of virtue in inauthentic ways, or over-using the terms when not actually undertaking teaching from that perspective risks backfiring on educators [2, p.363]. He encourages intellectual virtue language to "be integrated into statements of course goals and objectives" [2, p.366]. This is synergistic with ACRL recommendations to view IL frames as outlines to be developed further. In particular, "to develop resources such as curriculum guides, concept maps, and assessment instruments to supplement the core set of materials in the frames" [30]. Character concepts would be incorporated at this stage.

It is also important to note that IL educational programmes should not only make virtues explicit, but should also consider how such virtues are developed in children (i.e. process aspects). In relation, development of character should be viewed as an incremental and iterative process [2]. Baehr argues:

Character virtues arise through the practice or repetition of virtuous actions. Applied to intellectual virtues, the idea is that the traits in question develop through thinking, reading, interpreting, reflecting, analyzing, and discussing academic content in ways that are inquisitive, attentive, careful, thorough, [and] honest." [2, p.507].

Such principles of incremental learning are again synergistic with recommended approaches to IL education. For example, the ACRL framework, whilst acknowledging that single classes in IL have value, nonetheless recommends that IL education be viewed as a gradual process of learning transfer. In addition, it is important to recognise that the cognitive dispositions being developed require deep understanding, and require sufficient time be allocated to desired learning outcomes. Baehr recommends that: "... if we want to do what we can to ensure that our classes have a positive impact on the intellectual character of our students, we would do well to ask ourselves: "How well does my allotment of the time I have with my students reflect this pedagogical goal?" [2, p.292]. Further, careful consideration must be given to how to incorporate character development into IL education, and development of appropriate teaching and learning resources. We reserve exploration of this challenge for future research. 


\section{$7 \quad$ Limitations}

The paper provides the first critique of IL education models from a virtue epistemology perspective; however, our qualitative analysis is open to subjective interpretation. Further independent assessment would verify findings. Other frameworks of virtue epistemology could also have been considered, e.g. Rithchart, and Sockett [31-32]. Further, our analysis is limited to a sample of IL models. Analysis of further IL models would establish generalisability of findings. In relation, our methodology provides a repeatable approach for examination of both our sample and further IL models.

\section{Further research}

We position the development of intellectual character in children's online information behaviours as an understudied topic of significant societal concern, and encourage further research. In particular:

1. Further theoretical refinement of IL education models to explicitly incorporate application of intellectual character virtues.

2. Empirical studies with children to explore appropriate methods of intellectual character development to inform IL education programmes.

3. Analysis of current IL education for practitioners to consider how VE concepts can be introduced into the professional body of knowledge

\section{Conclusions}

The cultivation of character in children to foster virtuous citizenship must now consider behaviours in both the physical and digital space, and the concept of digital citizenship. We have argued that widely reported issues such as misinformation and disinformation extend IL education beyond considerations of ability to considerations of intellectual character; however, to date, the latter appears an understudied topic within IL education. Further, we have identified limited presence of concepts of intellectual character in our sample of IL models, with none explicit, and all subject to interpretation. If we accept that the development of character in children's' online information behaviours is indeed an important aspect of IL Education, much further research attention appears required to put into practice.

\section{References}

1. Meyer, M.J. “character.” In R. Audi (Ed.), The Cambridge Dictionary of Philosophy (3rd ed.). CUP. (2015).

2. Baehr, J. Cultivating Good Minds: A Philosophical \& Practical Guide to Educating for Intellectual Virtues (2015) 
3. OFCOM Children's Media Lives - Year 4 Findings. 2017. Available from: https://www.ofcom.org.uk (2017)

4. NSPCC. Online abuse: facts and statistics. 2018. Available from: https://www.nspcc.org.uk

5. Bullying. No Way. Available from: https://bullyingnoway.gov.au/

6. CCDC. Youth Risk Behavior Surveillance - United States. Surveillance Summaries 65(6) (2015)

7. UNESCO. Measuring cyberbullying and online risks for children. Available from: https://en.unesco.org (2017)

8. OFCOM. Children and Parents - media use and attitudes report. Available from: https://www.ofcom.org.uk (2017)

9. Harris, B.R. Values: The invisible "ante" in information literacy learning? Reference Services Review, 36(4), 424-437. (2008).

10. Smith, L. Towards a model of critical information literacy instruction for the development of political agency. Journal of Information Literacy, [S.1.], v. 7, n. 2, p. 15-32, Nov. (2013).

11. Bingham, T.J., Wirjapranata, J. \& Bartley, A. Building resilience and resourcefulness. Information and Learning Science, 118 (7), 433-446. (2017).

12. Farmer, L.S.J. Teaching ETHICS to teens via school library reference services. The Catholic Library World, 86(4), 242-250. (2016).

13. Hobbs, R. Teach the conspiracies. Knowledge Quest, 46(1), 16-24. (2017).

14. Rinne, N.A. The new framework: A truth-less construction just waiting to be scrapped? Reference Services Review, 45(1), 54-66. (2017).

15. Saunders, L. Connecting information literacy and social justice: Why and how. Communications in Information Literacy, 11(1), 55-75. (2017).

16. Dow, P.E. Virtuous Minds: Intellectual Character Development. Intervarsity Press. (2013) 17. Walker, D.I., Roberts, M.P., \& Kristjánsson, K. Towards a new era of character education in theory and in practice, Educational Review, 67:1 (2013)

18. Baehr, J. The Inquiring Mind: On Intellectual Virtues and Virtue Epistemology. OUP (2011)

19. CILIP. Definition of Information Literacy. Information Literacy Group. (2018).

20. American Library Association. Presidential Committee on Information Literacy: final report. Chicago: American Library Association (1989)

21. Berelson, B. Content Analysis in Communication Research. Michigan Free Press, 1952.

22. Bryman, A. Social research methods. Oxford University Press. (2015).

23. Aristotle. Nichomachean Ethics. Book 1. Chapter 2.

24. Ohler, J. Digital Citizenship Means Character Education for the Digital Age, Kappa Delta Pi Record, 47 : sup1, 25-27, (2011).

25. Wilson, T.D. Models in information behaviour research. Journal of documentation, 55(3), 249-270. (1999).

26. Kuhlthau, C.C. Seeking meaning: A process approach to library and information services. Libraries Unlimited Incorporated. (2004).

27. Welcome to the Big6. Available from: http://big6.com/

28. Eisenberg, M.B. and Berkowitz, R.E. Curriculum Initiative: An Agenda and Strategy for Library Media Programs. Ablex Publishing Corporation. (1988).

29. Eisenberg, M.B. and Berkowitz, R.E. Information Problem-Solving: The Big Six Skills Approach to Library \& Information Skills Instruction. Ablex Publishing Corporation. (1990).

30. ACRL. Framework for Information Literacy for Higher Education. Chicago, (2016).

31. Ritchart, R. Intellectual Character: What it is, why it matters, and how to get it. Jossey-Bass. (2002).

32. Sockett, H. Knowledge and Virtue in Teaching and Learning: The Primacy of Dispositions. Routledge. (2002). 